LA-7609-MS

Informal Report

UC-11 and UC-70

Issued: January 1979

\title{
Applicability of Microautoradiography to Sorption Studies
}

\author{
J. L. Thompson* \\ K. Wolfsberg
}

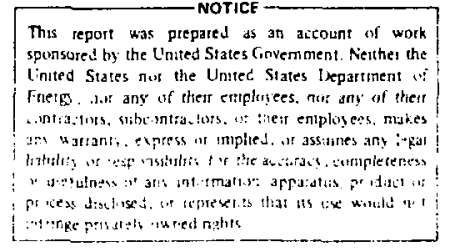

*Visiting Staff Member. Idaho State University, Pocatello, ID 83201.

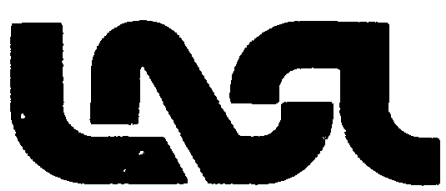


APPLICABILITY OF MICROAUTORADIOGRAPHY TO SORPTION STUDIES

by

J. L. Thompson and K. Wolfsberg

ABSTRACT

The technique of microautoradiography was applied to the study of the sorption of uranium and americium on five rock types which exist at the Nevada Test Site. It was found that autoradiograms could be prepared in a few days which would allow the specific minerals responsible for sorption to be identified. Furthermore, the state of aggregation of the sorbed species was clearly indicated. It was concluded that microautoradiography was a useful adjunct to currently used methods for studying sorption of certain radionuclides.

\section{INTRODUCTION}

The Nuclear Chemistry Group at Los Alamos Scientific Laboratory is currently involved in a number of geochemical projects, several of which involve the study of the behavior of radionuclides in various geologic media. Reports concerning the migration of radionuclides from the region of an underground nuclear explosion at the Nevada Test site, ${ }^{1}$ and describing sorption-desorption of uranium and certain fission products in alluvium, ${ }^{2}$ granite, ${ }^{3}$ argillite, ${ }^{4}$ and tuff ${ }^{5}$ have been issued recently. The work described in this report was undertaken as a possible means of extending these studies of the interaction of certain radionuclides with a variety of rock types, including those found at the Nevada Test Site. The specific objective of this work was to determine whether the technique of microautoradiography might be used to define which minerals in a given type 
of rock were responsible for sorbing the radionuclide of interest.

Autoradiography, the use of emulsions to determine the distribution of radioactive material, originated with Becquerel in 1896. In the early decades of the twentieth century this technique was commonly used for detecting and characterizing radionuclides. An extensive review of the use of emulsions for radioactivity measurements was published by Yagoda ${ }^{6}$ in 1949. Al though the advent of modern counting equipment has diminished reliance on nuclear emulsions as detection devices, autoradiography is still used in medical and biological research, in metallurgy for surface studies, ${ }^{7}$ and analys is of elemental distribution. ${ }^{8}$ Autoradiography has been employed to determine the distribution of radioactive elements in geologic media (Ref. 1, Chapter 7), but we have been unable to find literature reports concerning the use of this technique for sorption studies of radionuclides on minerals. What follows, then, is a description of the application of an old technique to aid in a contemporary research project.

\section{QUESTIONS CONCERNING THE APPLICATION OF AUTORADIOGRAPHY TO SORPTION} STUDIES

At the start of this project several questions concerning the possible use of autoradiography were unresolved.

A. Would it be possible to cause enough radioactivity to be sorbed on a given mineral in a rock specimen so that an autoradiogram could be prepared in a reasonable time?

B. Would it be possible to handle the emulsion in such a way that under microscopic examination the specific site (i.e., mineral) from which the activity originated could be identified?

c. Would the information gained be unique, or could it be obtained as readily by other analytical methods?

D. Would the technique prove to be applicable to a variety of nuclides and rock types?

These questions have now been resolved, and in the following section the experimental details, which justify affirmative answers to them, are reviewed. 


\section{EXPERIMENTAL METHOD AND RESULTS}

A. Sorption of Radionuclides

All of the rock types studied in this project were obtained from the Nevada Test Site. They include tuffaceous alluvium, argillite from the Eleana formation, granite from the Climax Stock area, and tuff samples from two different depths from drill site $J-13$ in Jackass Flat. ${ }^{9}$ Thin sections, ground and polished to about $30 \mu \mathrm{m}$ thickness on glass plates, were used in these studies. Kodak AR. 10 strippable emulsion was used for track detection. In order to have a reasonable density of alpha tracks in this material, it is necessary to expose the emulsion to $10^{6}$ to $10^{7}$ alpha particles per square centimeter. The desired exposure times were not to exceed several days in duration. Therefore, activity levels of the sorbed nuclides in the range of $10^{3}$ to $10^{4}$ dis $\mathrm{min}^{-1}$ were needed. Two methods were developed for transferring the activity from the solution to the material under study. The simpler method was to place a 50- $\mu$ l drop of the solution containing the radionuclide of interest in the rock thin section and to store it in a closed container saturated with water vapor. Despite the saturated atmosphere, it was found that appreciable evaporation from the droplet would occur, and contact times were thus limited to periods no longer than a few hours. Another technique was devised which allowed contact times of up to several days without the drcplet evaporating. A washer, 4 to $7 \mathrm{~mm}$ high, cut from smallbore Tygon tubing and clamped against the thin section served as reservoir for the 50- $\mu$ ldroplet. An aluminum covering plate prevented evaporation from the reservoir, and the small void space minimized internal evaporation.

Using these methods of contacting radioactive solutions with thin sections, it was possible to transfer sufficient activity of ${ }^{233} U(V I)$ or ${ }^{241}$ Am from 50- $\mu$ l droplets of solutions with activities in the range of $10^{6}$ to $10^{7}$ dis $\min ^{-1} \mathrm{~m}^{-1}$. Table I indicates representative percentages of activity transferred from the solution to the thin section and shows the rather wide variation which occurred in the case of americium. 
TABLE I

SORPTION ON THIN SECTIONS

Percent Sorbed

\begin{tabular}{|c|c|c|c|c|c|}
\hline Nuclide & Time $(h)$ & A1Tuvium & Argillite & Granite & Tuff \\
\hline${ }^{23} 3_{U}$ & 3 & 3 & 2 & 7 & $2-4$ \\
\hline${ }^{247}$ Am & 3 & $12-27$ & $1-20$ & $2-45$ & $6-26$ \\
\hline${ }^{241}{ }_{\mathrm{Am}}$ & 15 & & 29 & & $30-36$ \\
\hline${ }^{241} \mathrm{Am}$ & 21 & & & 5-11 & \\
\hline $241_{\mathrm{Am}}$ & 52 & 6 & & & \\
\hline
\end{tabular}

Perhaps part of the variability of sorption efficiency evidenced in the above table may be attributed to the characteristics of the solution containing the radionuclide. The solutions were prepared with water from the original geologic site of the rock type (alluvium, ${ }^{2}$ granite, ${ }^{3}$ tuff ${ }^{5}$ ) or with water synthesized to be similar to that found at the geologic site (argillite ${ }^{4}$ ). The radionuclides, initially in acid solution, were taken to dryness over a steam bath in polyethlene tubes and then redissolved in the appropriate ground waters, which had $\mathrm{pH}$ values of 8.0 to 8.2 . Solutions of ${ }^{233} \mathrm{U}$, prepared in this manner and stored in screw cap polyethylene bottles, were quite stabie, but the ${ }^{241}$ Am solutions tended to lose activity with time. This loss was especiaily pronounced with the solutions prepared with the Climax Stock granite water. A number of processes, including adsciption, polymer or colloid formation, precipitation, and air oxidation, might be involved in this activity loss. The autoradiograms of ${ }^{241}$ Am gave some clues concerning the behavior of this nuclide, and this topic will be discussed again in Section $E$ below. 


\section{B. Mounting of the Emulsion}

After the thin section was contacted with the ground water, spiked with ${ }^{233} \mathrm{U}$ or ${ }^{241} \mathrm{Am}$ for an appropriate time, it was rinsed with distilled water, air-dried, and placed under a thin-window methane-flow proportional counter to determine the amount of activity sorbed. The thin section was then coated with a thin layer of collodion by immersing it momentarily in a solution of $4 \mathrm{~g}$ parlodion in $200 \mathrm{ml}$ methyl alcohol and $200 \mathrm{~m} 2$ ethyl ether. This coating protected the sorbed material from contact with water during subsequent operations. By the same technique, a thin coating of gelatin was added over the collodion, using a solution containing $2 \mathrm{~g}$ gelatin and $0.25 \mathrm{~g} \mathrm{KCr}\left(\mathrm{SO}_{4}\right)_{2} \cdot 12 \mathrm{H}_{2} \mathrm{O}$ in $400 \mathrm{ml}$ water. The gelatin coating provided an adherent substrate for the strippable emulsion. The alpha activity level of ${ }^{241}$ Am was not affected by these coatings, and the activity of the slightly lower energy alpha particles from ${ }^{233} \mathrm{U}$ was attenuated only 2 or 3 percent. A small piece of Kodak AR.10 emulsion was floated on the surface of a dilute sucrose- $\mathrm{KBr}$ solution (20 g sucrose and $0.01 \mathrm{~g} \mathrm{KBr}$ per $\mathrm{L}$ ), and the thin section brought into contact with the emulsion at an angle from below, lifting the emulsion off the surface of the solution and onto the thin section.

\section{Exposure}

The emulsion was mounted in a darkroom using a red safelight. The thin section with the emulsion was placed in a light-tight box at room temperature during the exposure period. This period was of sufficient duration that $10^{6}$ to $10^{7}$ disintegrations of the sorbed nuclide would occur. The surface exposure of $10^{6}$ to $10^{7}$ alpha particles $\mathrm{cm}^{-2}$ yielded a sufficient number of alpha tracks in the emulsion to indicate the distribution of the sorbed nuclide on the thin section.

\section{Development}

On completion of the exposure, the emulsion was developed and fixed using Kodak D-19 developer and Kcdax Fixer, agail illuminating with a red safelight. The recommended times were followed in the processing: 5 min in the developer, $1 \mathrm{~min}$ of washing in water, $3 \mathrm{~min}$ in the fixing solution, and 5 min of final washing. The emulsion continued to adhere to the 
thin section throughout the processing and dried to a nearly transparent coating on the thin section.

E. Ana?ysis

The thin sections with the developed emulsion coatings were examined using a Leitz Ortholux 2 Pol BK microscope fitted with a binocular eyepiece, polarizer, and attachments for Polaroid and 35-mm cameras. The alpha tracks were generally viewed using 500X magnification and transmitted light, although reflected light: was occasionaliy used. The microscope could be focused on the tracks in the emulsion layer, which appeared as dark lines against the unfocused background of the minerals in the thin section. The al bind tracks varied in length, primarily because of their orientation with respest to the viewer, with the longest tracks being 15 to $20 \mu \mathrm{m}$ in length. Background tracks were few in number, and emulsion development due to chemicals or light appeared quite different from the alpha tracks. The concentration of nuclide sorbed at a particular site was indicated by the density of the tracks (Fig. 1). Larger concentrations produced "stars" with many tracks radiating from a single point (Fig. 2). The ratio of stars to single tracks gave a measure of the state of aggregation of the material deposited on the surface of the thin section.

A detailed analysis of the mineral phases responsible for sorption by the thin sections is in progress; however, the following qualitative observations may be made.

Uranium. In each of the rock types uranium appeared to sorb preferentially on certain of the minerals. Clay material appeared to sorb strongly, while there was little sorption on quartz. The amount of sorption seemed to be constant and predictable from orie experinent to the next. Occasionaily, the border of the solution contact area showed a somewhat higher density of tracks. This occurred when the solution volume had been appreciably reduced due to evaporation and probably was the result of deposition connected with the drying.

Americium. In general, americium transferred activity from the solution to the rock substrate more readily than did uranium (VI). However, 


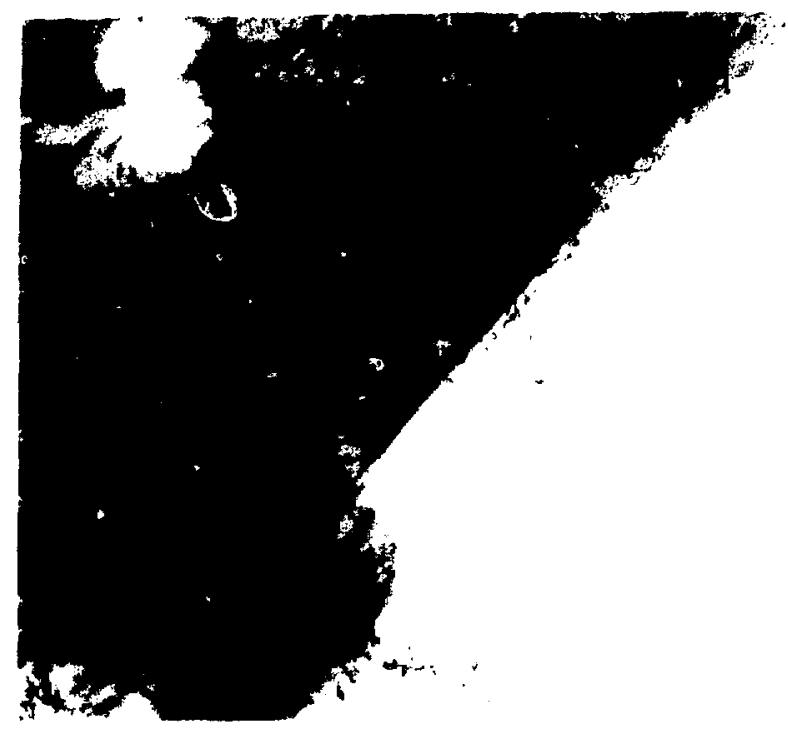

Fig. 1. Autoradingraph of $233_{U}$ (VI) sorbed on Climax Stock granite $(500 \times)$.
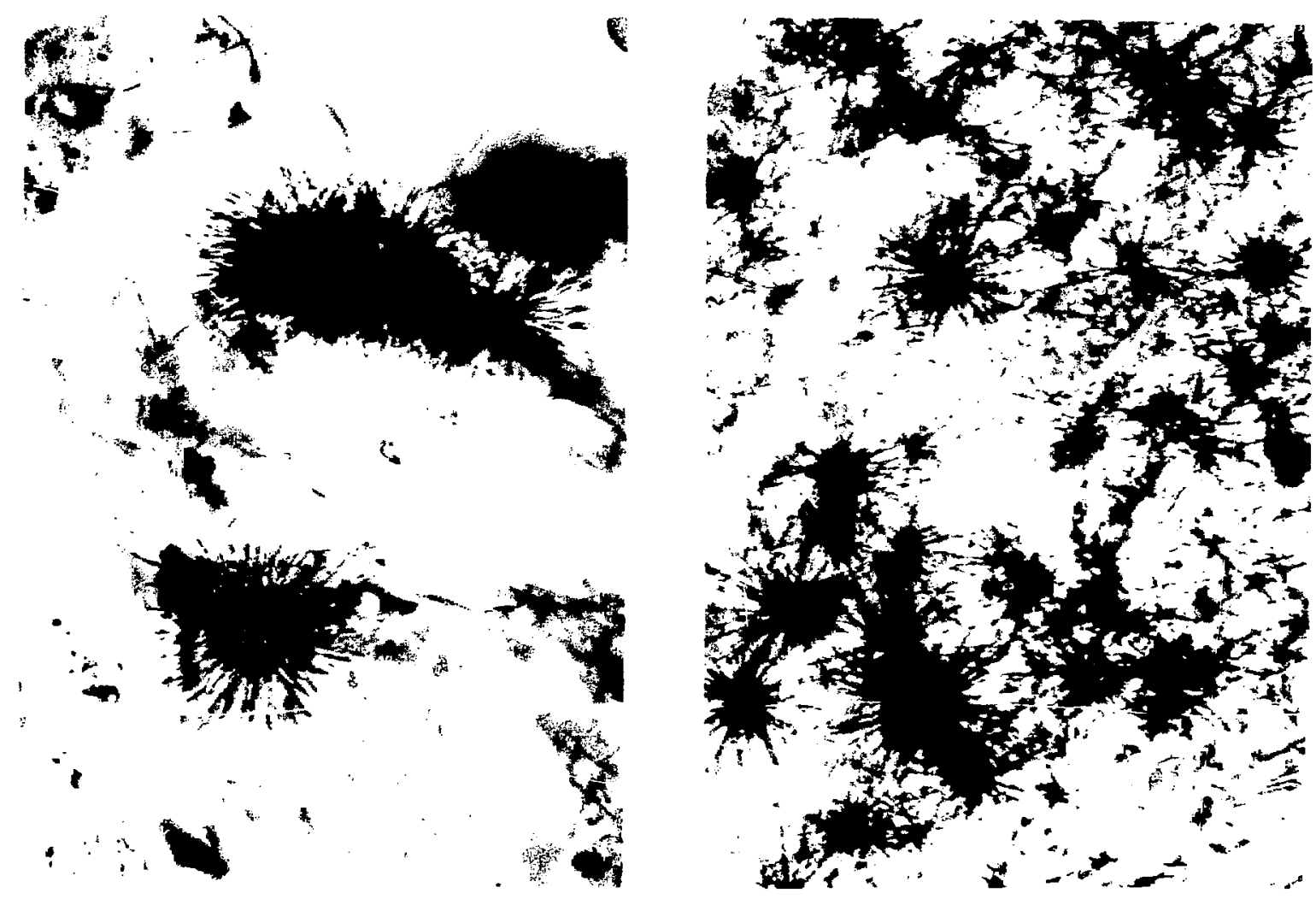

Fig. 2. Autoradiograph of ${ }^{23} 3 \mathrm{U}$ sorbed on Frenchman Flat a 17 uvium (500X).

Fig. 3. Autoradiograph of ${ }^{241} \mathrm{Am}$ sorbed on Climax Stock granite $(500 x)$. 
the distribution of sorption sites was noticably less specific for americium than for uranium. On granite the americium was deposited generally in an aggregated form as evidenced by the ratio of stars to single tracks (Fig. 3). On the alluvium, tuff, and argillite the tracks were generally single (Figs. 4, 5, 6). If any of the spiked ground waters were left exposed to the atmosphere for longer than a half hour, a dense ring of tracks would appear where the edge of the droplet was. If the droplet was contzined by the Tygon washer, the ring would not be present. Apparently at the air-solutior-solid interface some process (perhaps formation of inscisble oxy compounds or polymers) was taking place, resulting in deposition of the americium irrespective of the type of underlying mineral. This phenomenon may be related to the observation of Fried et a 1. 10 that americium (and plutonium) form insoluble deposits when allowed to dry.

\section{CONCLUSIONS}

The questions identified above (Section II) concerning whether autoradiography could be successfully applied to sorption studies have been resolved. It is possibie to prepare autoradiograms in relatively short times using modest levels of activity. Solutions of ${ }^{233} \mathrm{U}$ or ${ }^{241}$ Am with activities of $10^{6}$ to $10^{7}$ dis $\mathrm{min}^{-1} \mathrm{~m}^{-1}$ contacted with several different types of rock for a few hours give sufficient transfer of activity to produce good quality radiograms in exposure times not exceeding a few days. The radiograms produced by this technique enable one to determine very precisely where the sorbed species is located. The density of tracks can be directly correlated with the tendency of a mineral to sorb the radioactive species, and particuiariy good sorption sites are clearly indicated by stars in the developed emulsion. The emulsion remains in contact with the substrate throughout the processing, thereby maintaining the registry of tracks and site origin. The uncertainty concerning the origin of a single track is of the order of a track length $(<20 \mu \mathrm{m})$, while the uncertainty of the origin of a star is a few jum. The information gained from the autoradiograph is valuable in that the specific sorption 


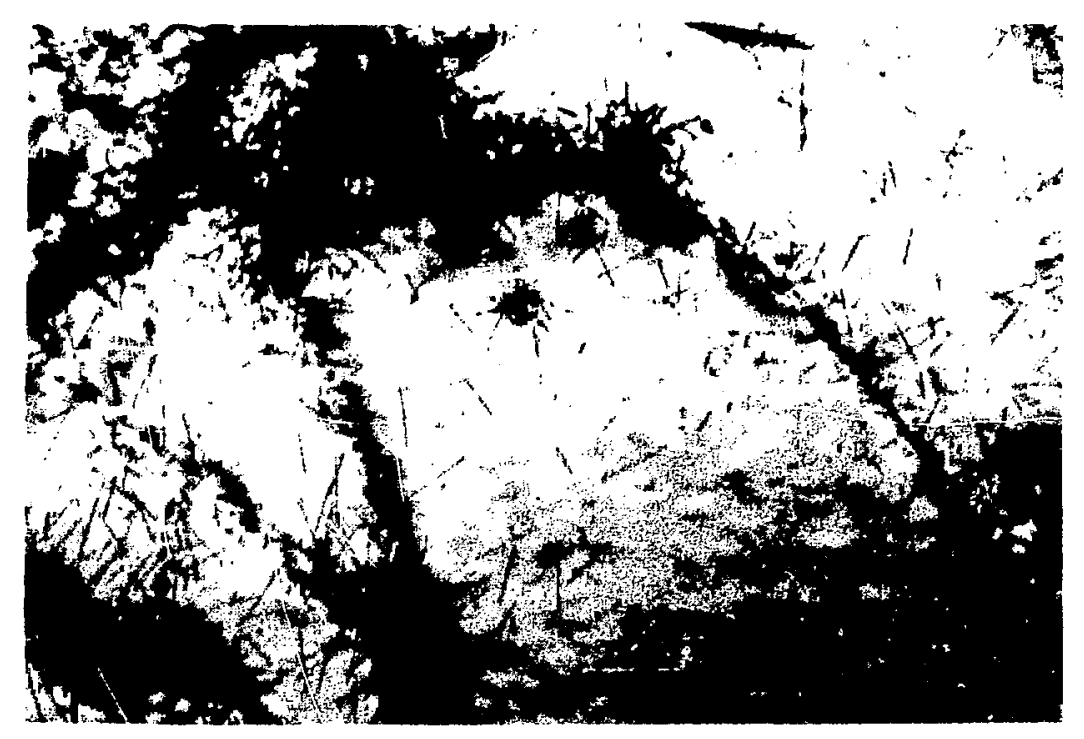

Fiq. 4. Autoradiograph of ${ }^{241}$ Am sorbed on Jackass Flat tuff (core 26) (500x).

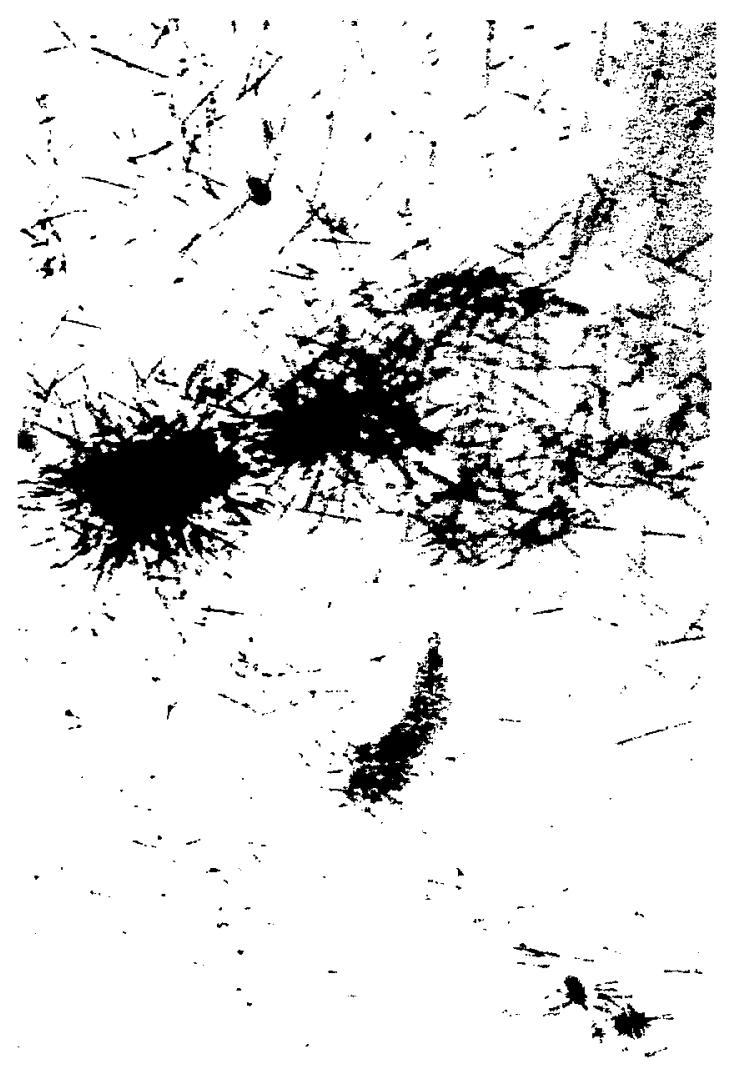

Fig. 5. Autoradiograph of ${ }^{241} \mathrm{Am}$ sorbed on Jackass Flat tuff (core 25) $(500 x)$.

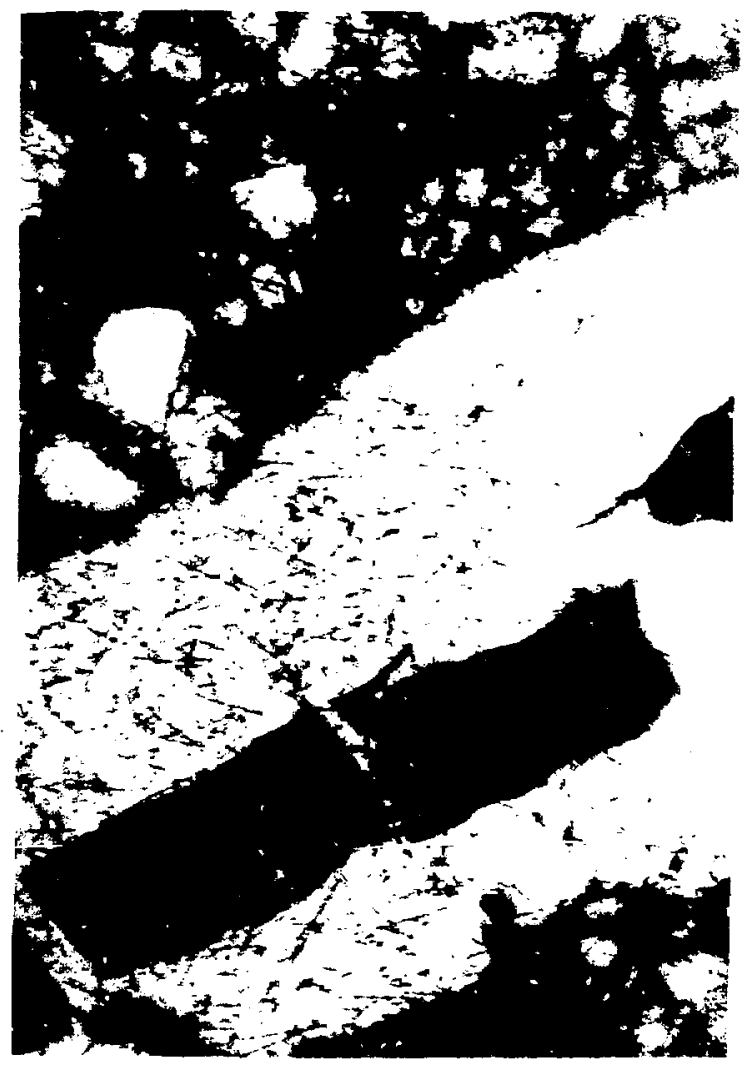

Fig. 6. Autoradiograph of 24 Am sorbed on Eleana arqillite (500x). 
site is identified, and the degree of aggregation of the sorbed species is indicated.

Elemental photomicroscopy with an electron microprobe, which has horizonal and vertical resolution of the order of $2 \mu \mathrm{m}$, may also yield information on sorption sites. However, sensitivities, which vary with the element, are in the 0.01 to 0.02 percent range at best. So, although autoradiography is not unique to this type of work, it is a much cheaper and simpler technique and has a high sensitivity.

The extent of sorption is not quantitatively measured in autoradiography; hence, it does not compete with column or batch methods used to determine distribution coefficients. It does, however, provide some insight into the sorption process because the state of aggregation of the sorbed particles is indicaced. The technique of microautoradiography has proven to be applicable for sorption studies of two radionuclides on five different rock materials. There seems to be no reason why other alpha-emitting or spontaneous-fissioning transuranic elements might not be utilizec' in similar studies. If the problems associated with longer ranges and lower track visibility of beta particles could be solved, this technique might be applied to a much wider group of radionuclides, especially to the fission products. Even if the method is limited to alpha-emitting ruclides, however, it does appear to be a useful adjunct to existing ways of studying sorption phenomena. 


\section{ACKNOWLEDGMENTS}

The authors wish to thank G. A. Cowan and J. E. Sattizahn for their administrative support of this work and the staff of Group CNC-11 for assistance in various aspects of the project. B. R. Erdal, W. R. Daniels, D. C. Hoffman, and J. R. Smyth contributed generously of their time and expertise. The thin sections were prepared by $D$. Mann and $K$. Ferdinand. One of the authors (JLT) acknowledges financial support by the Associated Western Universities, Inc.

\section{REFERENCES}

1. D. C. Hoffman, R. Stone, and W. W. Dudley, Jr., "Radioactivity in the Underground Environment of the Cambric Nuclear Explosion at the Nevada Test Site," Los Alamos Scientific Laboratory report LA-6877-MS (July 1977).

2. K. Wolfsberg, "Sorption-Desorption Studies of Nevada Test Site Alluvium and Leaching Studies of Nuclear Test Debris," Los Alamos Scientific Laboratory report LA-7216-MS (April 1978).

3. B. R. Erdal, R. D. Aguilar, B. P. Bayhurst, W. R. Daniels, C. J. Duffy, F. 0. Lawrence, S. Maestas, P. Q. Oliver, and K. Wolfsberg, "SorptionDesorption Studies on Granite," Los Alamos Scientific Laboratory report LA-7456-MS (to be published).

4. B. R. Erdal, R. D. Aguilar, B. P. Bayhurst, P. Q. 01 iver, and K. Wolfsberg, "Sorption-Desorption Studies on Argillite," Los Alamos Scientific Laboratory report LA-7455-MS (to be published).

5. K. Wolfsberg, B. P. Bayhurst, W. R. Daniels, B. R. Erdal, F. O. Lawrence, and $S$. Maestas, "Sorption Desorption Studies on Tuff," L.os Alamos Scientific Laboratory report LA-7480-MS (to be published).

6. H. Yagoda, Radioactive Measurements kijth Nuclear Emulsions, John Wiley \& Sons, Inc., New York, 1949.

7. J. A. Kennan and G. B. Larrabee, "Radioisotope Techniques", in Characterization of Solid Surfaces, P. F. Kane and G. B. Larrabee, Eds.. (PTenum, New York, 1974) pp. 247-273. 
8. D. R. Green, D. E. Rasmussen, and W. H. Gray, "Autoradiographic Measurements of Pu Distribution in Mixed-Oxide Nuclear Fuel," Hanford Engineering Development Laboratory report HEDL-TME-76-53 3Sept. 1976).

9. G. Heiken and M. L. Bevier, "Petrology of Tuff Units from the J-13 Drill Site, Jackass Flats, Nevada," (to be published).

10. S. Fried, A. M. Friedman, R. Atcher, and J. Hines, "Retention of plutonium and Americium by Rock," Science 196, 1087 (1977). 